Original Article

\title{
Hospital-based pilot study on partially dentate and edentate patients to evaluate disparity between prosthodontic treatment demand and need: A cross-sectional sociodemographic study
}

\author{
Sumant Kumar Singh ${ }^{a}$, Habib Ahmad Alvi ${ }^{b}$, Ramashankar ${ }^{c}$, \\ Saumyendra V. Singh ${ }^{d, *}$, Niraj Mishra ${ }^{c}$, Kamleshwar Singh ${ }^{c}$, \\ Deeksha Arya ${ }^{\mathrm{c}}$ \\ ${ }^{a}$ Resident, Department of Prosthodontics and Dental Material Sciences, Faculty of Dental Sciences, KG Medical \\ University UP, Lucknow, Uttar Pradesh, India \\ ${ }^{\mathrm{b}}$ Retired Professor and Head, Department of Prosthodontics and Dental Material Sciences, Faculty of Dental Sciences, \\ KG Medical University UP, Lucknow, Uttar Pradesh, India \\ ${ }^{\mathrm{c}}$ Associate Professor, Department of Prosthodontics and Dental Material Sciences, Faculty of Dental Sciences, KG \\ Medical University UP, Lucknow, Uttar Pradesh, India \\ d Professor Junior Grade, Department of Prosthodontics and Dental Material Sciences, Faculty of Dental Sciences, KG \\ Medical University UP, Lucknow, Uttar Pradesh, India
}

\section{A R T I C L E I N F O}

Article history:

Received 16 July 2016

Accepted 22 October 2016

Available online 8 November 2016

Keywords:

Patient demand

Patient need

Implants

Fixed prosthodontics

Removable prosthodontics

\begin{abstract}
A B S T R A C T
Objectives and background data: Urban India has seen dramatic improvements in per capita income, life expectancy and educational level in the past century. This should translate to better awareness and utilization of prosthodontic treatment options. The aim of this study was to gauge the veracity of the above hypothesis.

Materials and methods: A total of 1200 partially dentate and edentate patients visiting 2 dental hospitals for prosthodontic rehabilitation were randomly selected and administered a questionnaire and clinical examination. Data including distance of patient residence from hospital facility, patient desired prosthodontic treatment, prosthodontist's assessment of required treatment and disparity between demand and assessed treatment need were collected, evaluated, and statistically analyzed utilizing Graph Pad Prism Software with $\alpha=2$ and $p<0.05$.

Results: Forty-nine percent of the patients visiting the hospitals disagreed with professional advice. The reasons recorded for this included lack of awareness (39\%), financial constraints $(20 \%)$ and clinical limitations $(32 \%)(p<0.01)$.

Conclusion: A significant disparity was found between professional prosthodontic advice and patient desired management, possibly due to lack of understanding or communication
\end{abstract}

\footnotetext{
* Corresponding author at: 2/273, ViramKhand, Gomti Nagar, Lucknow, Uttar Pradesh, India. Tel.: +91 9415470702.

E-mail address: saumyendravsingh@rediffmail.com (S.V. Singh).

http://dx.doi.org/10.1016/j.cegh.2016.10.001

2213-3984/C 2016 INDIACLEN. Published by Elsevier, a division of RELX India, Pvt. Ltd. All rights reserved.
} 
between the prosthodontist and patient. This may be overcome by increasing awareness aids and programs in the hospital set up, and more time given to communication.

(C) 2016 INDIACLEN. Published by Elsevier, a division of RELX India, Pvt. Ltd. All rights

reserved.

\section{Introduction}

Though lagging behind other nations in terms of proportion of older adults, India has the second largest older adult population in the world (nearly 85 million). ${ }^{1-3}$ The prosthodontist, is amongst the most highly visited dental health professional by the aging population (as life span increases, so does incidence of tooth loss) and his/her responsibility does not end with fabrication of a good prosthesis. ${ }^{4} \mathrm{~A}$ patient who is not fully convinced about the prosthodontist's restorative recommendation may never be satisfied with her/his prosthesis, be it the comfort level or compliance.

Urban India has experienced dramatic changes in various fields in the past decades. India's per capita Income has risen $65.8 \%$ from 2002-03 to 2010-11. ${ }^{2}$ According to the WHO, the average life expectancy in India was 65 years in 2009 and 57 years in $1990 .^{3}$ This should translate to an increased interest in prosthodontic treatment and available options in patients. Higher income and a greater number of patients in aging population should raise demand and quality expectations of dental prosthetic treatment. ${ }^{4,5}$ Our conjecture was that dental hospitals should be visited by patients with high level of understanding about their prosthodontic need. The null hypothesis was that there would no disparity between patient demanded and needed prosthodontic treatment. It was also aimed to associate why patients wanted prosthodontic treatment and which type, with gender, age, education, economic condition, and distance of residence from hospital. $^{6-11}$

Patients' perceived needs and expectations are an essential part of the evidence-based model for prosthodontic treatment planning. Therefore, it is natural that not only clinical aspects of prosthodontics influence treatment needs. Human ability to adapt physically and psychologically to changes in the oral condition, when pain symptoms are absent, may act in addition to external factors such as environment and social context. Patients may choose to selectively perceive potential benefits or demands of a given treatment., ${ }^{9,10,12-15}$

The aim of this study was to study the relationship between socio-demographic factors of edentulous and partially dentate patients with prosthodontic demand and whether demand agreed with need. ${ }^{16-18}$

\section{Materials and methods}

This pilot, first of its kind, study was conducted in two dental hospitals in Lucknow, which is the capital of Uttar Pradesh, the most populous state of India, after obtaining approval from the Institutional Ethics Committee. These two institutes were selected randomly from six dental teaching hospitals of the city. Partially dentate or edentulous adult patients visiting the Department of Prosthodontics of these institutes (one government and one private aided) for rehabilitation for the first time were eligible to be selected for the study. The cross sectional study was done by means of a questionnaire and clinical examination and conducted over a period of 15 months. The study sample was collected for six months in one institute and for six months in the other institute. Three months were utilized for data collection, analysis and evaluation. (January 2015-April 2015). To avoid inter-institute comparison/bias, the data were collected without institute identification. For randomization, patients visiting the department on Mondays, Wednesdays and Fridays during the study period were considered. Each patient was first taken through the informed consent process, examined clinically and then administered a close ended, pre-validated, multiple choice questionnaire. Construct validity of the questionnaire was evaluated using average Congruency Percentage (Popham, 1978) in where experts computed the percentage of questions deemed be and then take average of all expert was calculated. The value was $94 \%$ (greater than $90 \%$ value = valid). Reliability of questionnaire was checked using Pearson correlation coefficient method and came out to be 0.8 (strong positive correlation). The questionnaire was available in English as well as Hindi (national language) to promote better understanding. Uneducated people were administered the questionnaire by a third party emphasizing confidentiality and avoiding suggestive questioning.

The details and the purpose of study were first explained to the patients. Patients were assured that all information collected would be strictly confidential. To control bias, patients selected for the study were assured that the interviewer would not be involved in their treatment and their participation in the study would not influence outcome or cost of treatment. The exclusion criteria were any systemic disease which could contraindicate a prosthodontic treatment protocol and previous prosthesis wearers. Of the 1327 patients who were approached, 127 had to be excluded either due to dissent to participate or systemic disease.

For clinical examination, pre-autoclaved sets of diagnostic instruments were used to assess the degree of edentulism and the treatment option/s for the patient, after studying the mandatory Orthopantomogram. Patients who had a single complete edentulous arch were included in the partially edentulous group (Table 1). A team of 3 prosthodontists was constituted for arriving at the preferred prosthodontist assessed treatment option, by evaluation of the residual ridge, length of edentulous span, abutment bone support and angulation, periodontal health, dental caries status, radiograph, financial condition of the patient etc. In case of lack of consensus even after discussion, the majority decision was considered. 
Table 1 - General characteristics of study sample.

\begin{tabular}{|c|c|c|c|}
\hline Characteristic & Category & Number $(n)$ & Percentage (\%) \\
\hline \multirow[t]{2}{*}{ Gender } & Male (M) & 636 & 53 \\
\hline & Female (F) & 564 & 47 \\
\hline \multirow[t]{3}{*}{ Age } & $<50$ years $(\mathrm{A} 1)$ & 489 & 41 \\
\hline & $50-65$ years (A2) & 432 & 36 \\
\hline & $>65$ years $(\mathrm{A} 3)$ & 279 & 23 \\
\hline \multirow[t]{3}{*}{ Education } & Uneducated (E0) & 456 & 38 \\
\hline & Up to 12 (E1) & 534 & 45 \\
\hline & Graduate or above (E2) & 210 & 18 \\
\hline \multirow[t]{3}{*}{ Income } & $<$ Rs. 3000 pm (I1) & 711 & 59 \\
\hline & Rs. $3000-$ Rs. 10,000 pm (I2) & 294 & 25 \\
\hline & $>$ Rs. 10,000 pm (I3) & 195 & 16 \\
\hline \multirow[t]{2}{*}{ Dental status } & Edentulous & 180 & 15 \\
\hline & Partially edentulous & 1020 & 85 \\
\hline
\end{tabular}

The first part of the questionnaire dealt with the biosocial (name, age, gender) and socioeconomic (educational status and monthly income) characteristics of the patient. The groups were loosely based on the modified Kuppuswami scale. ${ }^{19}$ This classification has been developed for low-income populations and is based on a subject's level of education, occupation, and household income. The sum total of these graded parameters determines the socio-economic status of an individual. The second part of the questionnaire consisted of an estimate of distance of patients' residence from the concerned dental institute, the reason for prosthesis requirement and patient preferred prosthetic treatment (demand). The professional advice of the prosthodontic team (need) was then noted. The team (not including the interviewer) then discussed with the patient their reason for selecting a particular treatment option/s.

This was followed by recording whether the patient demand agreed with need. The reason for disparity was recorded using close ended, categorical multiple choice options. Discrete (categorical) data were summarized in frequency and compared by using chi-square $\left(\chi^{2}\right)$ test, with $p<0.05$ considered statistically significant. All analyses were performed on Graph-Pad Prism software (Windows version 5.0).

\section{Results}

Table 1 showed age, gender, education and income distribution of the sample. While $85 \%$ of the sample was partially dentate (including single completely edentulous arch), 15\% required complete dentures. Table 2 showed a significant association $\left(\chi^{2}=83.25, p<0.0001\right)$ between age and distance of dental facility from residence of patients. For patients aged less than 50 years, the proportion of all distance groups were similar, while for the more than 65 years age group, the more

\section{Table 2 - Comparison of variables with distance of dental facility from residence of patients.}

\begin{tabular}{|c|c|c|c|c|}
\hline & $<2 \mathrm{~km}(\mathrm{D} 1)$ & 2-5 km (D2) & $>5 \mathrm{~km}(\mathrm{D} 3)$ & Total \\
\hline \multicolumn{5}{|c|}{ Comparison of age with distance of dental facility from residence of subject } \\
\hline$<50$ years (A1) & $135(28 \%)$ & $186(38 \%)$ & $168(34 \%)$ & $489(41 \%)$ \\
\hline 50-65 years (A2) & $147(34 \%)$ & $153(35 \%)$ & $132(31 \%)$ & $432(36 \%)$ \\
\hline \multirow[t]{2}{*}{$>65$ years $(\mathrm{A} 3)$} & $165(59 \%)$ & $75(27 \%)$ & $39(14 \%)$ & $279(23 \%)$ \\
\hline & \multicolumn{4}{|c|}{$\chi^{2}=83.25, p<0.0001$} \\
\hline \multicolumn{5}{|c|}{ Comparison of gender with distance of dental facility from residence of patients } \\
\hline Male (M) & $195(31 \%)$ & $192(30 \%)$ & $249(39 \%)$ & $636(53 \%)$ \\
\hline \multirow[t]{2}{*}{ Female (F) } & $252(45 \%)$ & $222(39 \%)$ & $90(16 \%)$ & $564(47 \%)$ \\
\hline & $\chi^{2}=79.99, p$ & & & \\
\hline \multicolumn{5}{|c|}{ Comparison of educational status with distance of dental facility from residence of patients } \\
\hline Uneducated (E0) & $330(72 \%)$ & $72(16 \%)$ & $54(12 \%)$ & $456(38 \%)$ \\
\hline Up to 12 (E1) & $81(15 \%)$ & $258(48 \%)$ & $195(37 \%)$ & $534(45 \%)$ \\
\hline \multirow[t]{2}{*}{ Graduate or above (E2) } & $36(17 \%)$ & $84(40 \%)$ & $90(43 \%)$ & $210(18 \%)$ \\
\hline & $\chi^{2}=393.60$ & & & \\
\hline \multicolumn{5}{|c|}{ Comparison of average monthly income with distance of dental facility from residence of patients } \\
\hline$<$ Rs. 3000 (I1) & 345 (49\%) & $231(32 \%)$ & $135(19 \%)$ & $711(59 \%)$ \\
\hline Rs. $3000-10,000$ (I2) & $72(24 \%)$ & $123(42 \%)$ & $99(34 \%)$ & $294(25 \%)$ \\
\hline \multirow[t]{2}{*}{$>$ Rs. 10,000 (I3) } & $30(15 \%)$ & $60(34 \%)$ & $105(54 \%)$ & 195 (16\%) \\
\hline & $\chi^{2}=138.20$ & & & \\
\hline Total & 447 (37\%) & $414(35 \%)$ & 339 (28\%) & 1200 \\
\hline
\end{tabular}


Table 3 - Comparison of variables with patient assessed reason of prosthesis requirement.

\begin{tabular}{|c|c|c|c|c|c|c|c|}
\hline & $\begin{array}{c}\text { Difficulty in } \\
\text { eating (R1) }\end{array}$ & $\begin{array}{c}\text { Social/esthetic } \\
\text { concern (R2) }\end{array}$ & $\begin{array}{c}\text { Health } \\
\text { concern (R3) }\end{array}$ & $\begin{array}{c}\text { Both R1 } \\
\text { and R2 (R4) }\end{array}$ & $\begin{array}{l}\text { All R1, R2 } \\
\text { and R3 (R5) }\end{array}$ & $\begin{array}{l}\text { Motivated by } \\
\text { others (R6) }\end{array}$ & Total \\
\hline \multicolumn{8}{|c|}{ Comparison of age with patient assessed reason of prosthesis requirement } \\
\hline$<50$ years $(\mathrm{A} 1)$ & $57(12 \%)$ & $258(53 \%)$ & $24(5 \%)$ & $75(15 \%)$ & $57(12 \%)$ & $18(4 \%)$ & 489 (41\%) \\
\hline $50-65$ years $(\mathrm{A} 2)$ & $195(45 \%)$ & $18(4 \%)$ & $96(22 \%)$ & $30(7 \%)$ & $12(3 \%)$ & 81 (19\%) & $432(36 \%)$ \\
\hline \multirow[t]{2}{*}{$>65$ years $(\mathrm{A} 3)$} & $108(39 \%)$ & $9(3 \%)$ & $60(22 \%)$ & $15(5 \%)$ & $6(2 \%)$ & $81(29 \%)$ & $279(23 \%)$ \\
\hline & \multicolumn{7}{|c|}{$\chi^{2}=588.60, p<0.0001$} \\
\hline \multicolumn{8}{|c|}{ Comparison of gender with patient assessed reason of prosthesis requirement } \\
\hline Male (M) & $252(40 \%)$ & $45(7 \%)$ & $150(24 \%)$ & $57(9 \%)$ & $57(9 \%)$ & $75(12 \%)$ & $636(53 \%)$ \\
\hline \multirow[t]{2}{*}{ Female (F) } & $108(19 \%)$ & $240(43 \%)$ & $30(5 \%)$ & $63(11 \%)$ & $18(4 \%)$ & $105(19 \%)$ & $564(47 \%)$ \\
\hline & \multicolumn{7}{|c|}{$\chi^{2}=293.30, p<0.0001$} \\
\hline \multicolumn{8}{|c|}{ Comparison of educational status with patient assessed reason of prosthesis requirement } \\
\hline Uneducated (E0) & $189(41 \%)$ & $21(5 \%)$ & $24(5 \%)$ & $21(5 \%)$ & $57(13 \%)$ & $144(32 \%)$ & $456(38 \%)$ \\
\hline Up to class 12 (E1) & $120(22 \%)$ & $210(39 \%)$ & $93(17 \%)$ & $63(12 \%)$ & $15(3 \%)$ & $33(6 \%)$ & $534(45 \%)$ \\
\hline \multirow[t]{2}{*}{ Graduate/above (E2) } & $51(24 \%)$ & $54(26 \%)$ & $63(30 \%)$ & $36(17 \%)$ & $3(1 \%)$ & $3(1 \%)$ & $210(18 \%)$ \\
\hline & \multicolumn{7}{|c|}{$\chi^{2}=429.10, p<0.0001$} \\
\hline \multicolumn{8}{|c|}{ Comparison of average monthly income with patient assessed reason of prosthesis requirement } \\
\hline$<$ Rs. 3000 (I1) & $294(41 \%)$ & $81(11 \%)$ & $60(8 \%)$ & $75(11 \%)$ & $57(8 \%)$ & $144(20 \%)$ & $711(59 \%)$ \\
\hline Rs. $3000-10,000$ (I2) & $57(19 \%)$ & $120(41 \%)$ & $54(18 \%)$ & $21(7 \%)$ & $9(3 \%)$ & $33(11 \%)$ & $294(25 \%)$ \\
\hline \multirow[t]{2}{*}{$>$ Rs. 10,000 (I3) } & $9(5 \%)$ & $84(43 \%)$ & $66(34 \%)$ & $24(12 \%)$ & $9(5 \%)$ & $3(1 \%)$ & $195(16 \%)$ \\
\hline & \multicolumn{7}{|c|}{$\chi^{2}=316.90, p<0.0001$} \\
\hline Total & $360(30 \%)$ & $285(24 \%)$ & $180(15 \%)$ & $120(10 \%)$ & $75(6 \%)$ & $180(15 \%)$ & 1200 \\
\hline
\end{tabular}

than $5 \mathrm{~km}$ distance was lesser. The proportion of the three distance groups was almost the same for males, while females coming from a distance greater than $5 \mathrm{~km}$ was lesser $\left(\chi^{2}=79.99, p<0.0001\right)$. Uneducated people coming from a closer distance were significantly more $\left(\chi^{2}=393.60\right.$, $p<0.0001)$. More educated subjects were ready to come from greater distances. A significant association between average monthly income and distance from facility was found $\left(\chi^{2}=138.20, p<0.0001\right)$.

Table 3 showed that difficulty in eating was the most important (30\%) patient assessed reason for prosthesis requirement, followed by social/esthetic concerns (24\%), health concerns and motivation by others (both 15\%). Younger subjects had more social/esthetic concerns $\left(\chi^{2}=588.60\right.$, $p<0.0001$ ), while older subjects had greater health concerns. Female patients had greater proportion of social/esthetic concerns $\left(\chi^{2}=293.30, p<0.0001\right)$ and more educated subjects had higher health concerns (30\%). For lower income group subjects, difficulty in eating and motivation by others as reason for prosthesis requirement were higher $\left(\chi^{2}=316.90, p<0.0001\right)$, while social/esthetic concerns (43\%) and health concerns (34\%) were more important for higher income subjects.

Table 4 showed that patients desired fixed partial dentures the most (56\%), demand for implants was about $9 \%$ and $6 \%$ of the patients left the choice of prosthesis to the dentist. In subjects less than 50 years of age the desire for fixed partial dentures was more $\left(\chi^{2}=214.50, p<0.0001\right)$, while in subjects aged more than 65 years the demand pattern was almost reverse of their younger counterparts. A lesser $\left(\chi^{2}=109.90\right.$, $p<0.0001)$ proportion of females left the prosthesis demand to the dentist. Graduates and more educated subjects had a high demand for fixed partial dentures (72\%) and implants $\left(\chi^{2}=150.10, p<0.0001\right)$. Similarly, higher income group subjects had greater fixed partial denture and implant demand (54\% and 31\% respectively).
Table 5 showed that lack of awareness (39\%) was the major reason of disparity between patient desired and prosthodontist preferred treatment option, followed by clinical reasons and financial limitations. In subjects aged more than 65 years age, lack of awareness (71\%) was found to be higher $\left(\chi^{2}=159.10, p<0.0001\right)$. In male patients the proportion of financial (37\%) and clinical reasons (35\%) was high, while in females lack of awareness was comparatively higher (49\%). For uneducated subjects, lack of awareness as the reason of disparity was highest (46\%), followed by financial limitations (28\%). For the highly educated group, clinical reasons (44\%) for disparity of opinion were higher $\left(\chi^{2}=86.19, p<0.0001\right)$. For the higher income group, clinical reasons (62\%) and unreasonable expectations (23\%) as causes of disparity were more significant $\left(\chi^{2}=139.60, p<0.0001\right)$.

\section{Discussion}

In an Indian survey by Nadgere et al. (2010) it was reported that there were few aging patients reporting for prosthetic treatment, as such patients gave a lower priority to dental health. Older people make extensive use of medical facilities but seem to underuse dental facilities. ${ }^{6}$ Another study showed that old age by itself did not seem to be a major factor in determining the use of dental services, when populations were stratified by dental status. ${ }^{7}$ Antczak and Branch (1985) stated that the belief that "oral problems are a part of growing old" was an important barrier in seeking dental treatment. ${ }^{8}$ It has also been stated that perception of need was an important determinant of dental care utilization. ${ }^{9}$

Distance of the patients' residence from the dental facility appeared to play a big role in their hospital attendance. Patients seeking prosthodontic treatment were significantly lesser in the greater than $5 \mathrm{~km}$ distance group. Our conjecture 
Table 4 - Comparison of variables with patients' demand.

Removable prosthesis (RP) $\quad$ Fixed prosthesis (FP) $\quad$ Implant (IMP) No opinion (NO)

Total

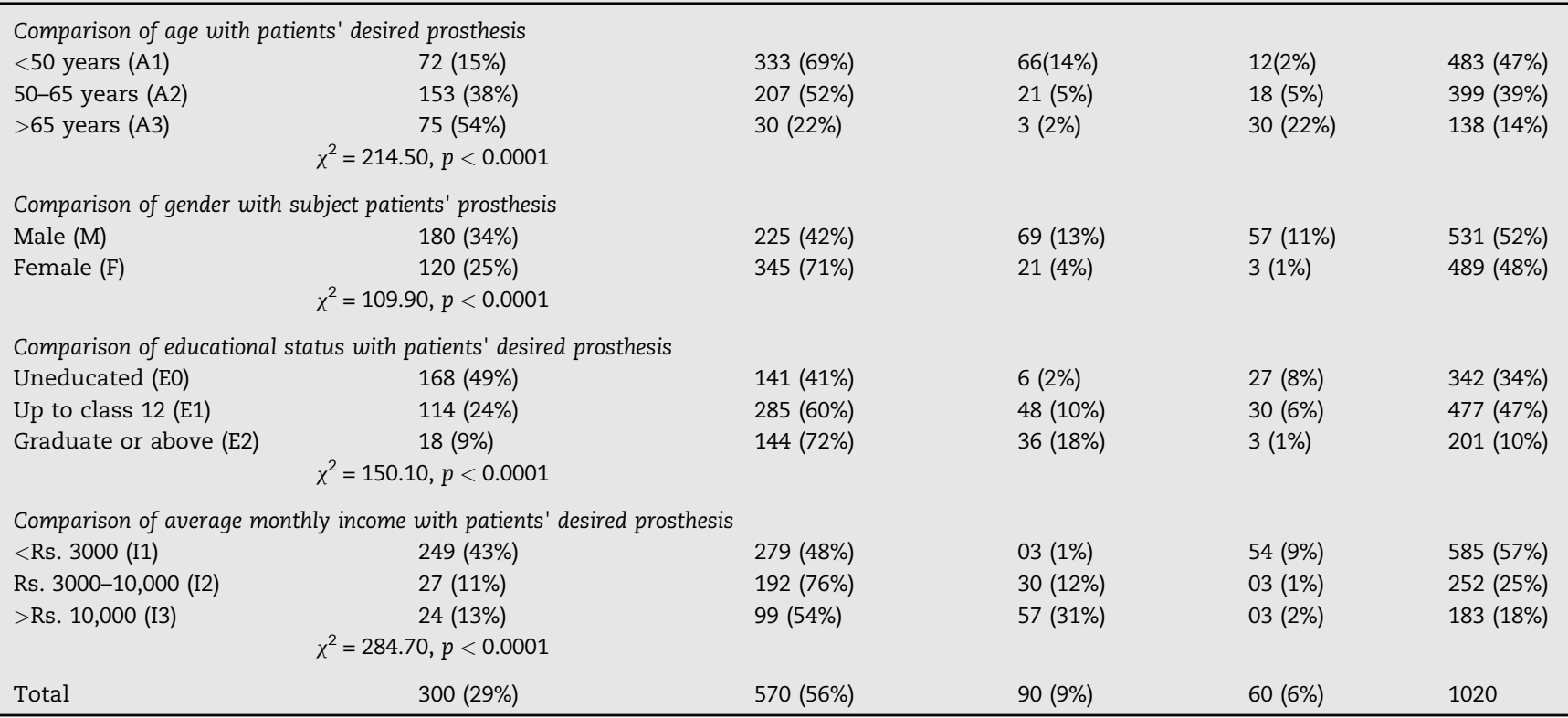

is that this may be because patients availed of a nearer dental facility, considered the trouble/expense of traveling a deterrent to rehabilitation or were plagued by lack of proper conveyance or mobility to reach the dental treatment center. Greater distance as an obstacle to seeking prosthetic treatment was seen prominently in women and older patients. Educationally and monetarily competent patients were less affected (Table 2).

While considering the reasons for approaching a prosthodontist, masticatory difficulty was the most important reason.
Social/esthetic concern came next and was found to be of significant importance in younger, female, higher income and more educated subjects (Table 3 ). However, poorer (20\%) and uneducated (32\%) patients were often urged into rehabilitation by others (Table 3). D'Souza et al. ${ }^{20}$ also reported that income and education were related to partial edentulism. In a contrasting study in Nigeria, it was reported that age, gender and socioeconomic status of patients had no statistically significant on the reason for demand and usage of complete dentures. ${ }^{21}$ Another study where participants were questioned

\section{Table 5 - Comparison of variables with possible reason of disparity between demand and need.}

$$
\text { Financial Clinical Lack of awareness Unreasonable expectation }
$$

Comparison of age with possible reason of disparity between patient desired and prosthodontist preferred treatment option

$\begin{array}{lllll}<50 \text { years (A1) } & 81(31 \%) & 66(25 \%) & 87(33 \%) & 27(10 \%) \\ 50-65 \text { years (A2) } & 09(8 \%) & 84(70 \%) & 21(18 \%) & 06(5 \%) \\ >65 \text { years (A3) } & 12(10 \%) & 12(10 \%) & 87(71 \%) & 12(10 \%) \\ & \chi^{2}=159.10, p<0.0001 & & \end{array}$

Comparison of gender with possible reason of disparity between patient desired and prosthodontist preferred treatment option

\begin{tabular}{|c|c|c|c|c|c|}
\hline Male (M) & 72 (37\%) & $69(35 \%)$ & $39(20 \%)$ & $15(8 \%)$ & 195 (39\%) \\
\hline Female (F) & $30(10 \%)$ & 93 (30\%) & 156 (49\%) & 30 (10\%) & 309 (61\%) \\
\hline
\end{tabular}

Comparison of educational status with possible reason of disparity between patient desired and prosthodontist preferred treatment option

\begin{tabular}{|c|c|c|c|c|c|}
\hline Uneducated (E0) & $72(28 \%)$ & $60(23 \%)$ & $120(46 \%)$ & $09(3 \%)$ & $261(52 \%)$ \\
\hline Up to class 12 (E1) & 27 (14\%) & 78 (41\%) & $66(35 \%)$ & $18(10 \%)$ & $189(38 \%)$ \\
\hline Graduate or above (E2) & $03(6 \%)$ & $24(44 \%)$ & 09 (17\%) & $18(33 \%)$ & 54 (11\%) \\
\hline
\end{tabular}

Graduate or above (E2) $\quad 03(6 \%) \quad 24(44 \%)$
$x^{2}=86.19, p<0.0001$

$09(17 \%)$

Comparison of average monthly income with possible reason of disparity between patient desired and prosthodontist preferred treatment option

\begin{tabular}{|c|c|c|c|c|c|}
\hline$<$ Rs. 3000 (I1) & $96(27 \%)$ & $72(20 \%)$ & $174(48 \%)$ & $18(5 \%)$ & $360(71 \%)$ \\
\hline Rs. $3000-10,000$ (I2) & $03(5 \%)$ & $42(64 \%)$ & $12(18 \%)$ & 09 (14\%) & $66(13 \%)$ \\
\hline \multirow{2}{*}{$>$ Rs. 10,000 (I3) } & $03(4 \%)$ & 48 (62\%) & 09 (12\%) & $18(23 \%)$ & $78(15 \%)$ \\
\hline & \multicolumn{5}{|c|}{$\chi^{2}=139.60, p<0.0001$} \\
\hline Total & $102(20 \%)$ & $162(32 \%)$ & $195(39 \%)$ & 45 (9\%) & 504 \\
\hline
\end{tabular}


regarding the most important teeth to be replaced, most participants (81\%) were concerned about having anterior rather than posterior teeth replaced. ${ }^{10}$ According to Öwal and Taylor, it was a common procedure to use fixed partial bridges to replace only the anterior missing teeth, leaving the posterior space untreated. ${ }^{11}$

The term "need" though simple, has many conceptual meanings and interpretations. Bradshaw (1972) presented categories of needs: normative need (professionally expressed), felt or subjective-need (patient or population wanted), expressed-need or demand which referred to feltneed turned into action. Walter et al. (2001) noted that "subjective need" rarely existed without normative need. Need was defined by Sheiham and Spencer in 1980 as the quantity of dental health care according to expert opinion, which returns the patient to dental health, as permitted by existing knowledge. ${ }^{12-15}$

A study by Vigild ${ }^{22}$ in 1993, on the institutionalized elderly found that professionally assessed dental treatment did not tally with true need. Vigild felt that this might be because such individuals were not in a condition to demand or benefit from such treatment. He further recommended that realistic or feasible need would be more appropriate than professionally determined or patient perceived need for such individuals, taking into account their physical and mental condition.

Among the various patient desired treatment options, the fixed partial denture demand was significantly high, because most patients reported that removable prostheses were troublesome in use and needed several appointments and time to adjust in the oral cavity. Also, such prostheses need to be regularly removed for cleaning and providing tissue rest, which was embarrassing, especially for females. Such patients were of the view that having a fixed prosthesis would make them feel more secure, without fear that the denture would fall out. Very few patients (6\%) came with the mindset of leaving the choice of treatment to the professional. The demand for dental implants, despite living in an urban set up with proper media, internet and mass communication facilities was quite less. As was expected, the better-educated and richer patients had higher demand for dental implants.

Similar findings have been reported where there were clear gender differences, when considering fixed partial denture therapy. A study by Mukatash et al. ${ }^{10}$ stated that psychological reasons, feeling of security and ease of maintenance were more important than functional and esthetic aspects of fixed partial denture therapy. Pedersen et al. (2005) ${ }^{7}$ found that among people with perceived need for dental care, those who cited cost as a barrier had a six fold higher probability of using dental care less than once per year, compared with those for whom cost was not a barrier. Similar findings were reported by other investigators who found household income was a major factor in predicting dental attendance..$^{23-25}$

After the team of prosthodontists in the present study had decided upon the preferable treatment option for a particular patient, they discussed their opinion with the subject. Disagreement between patient and professionals was duly recorded (which was quite high $49 \%$ ). The possible reason for disparity was also noted. These were: lack of awareness i.e. the patient was not aware of all treatment options; clinical reasons i.e. the patient had functional or anatomic limitations because of which his/her treatment of choice was not feasible; financial constraints of the patient; and unreasonable expectations, for example an edentulous patient with a severely resorbed residual ridge, who wants a retentive prosthesis and is unwilling to undergo surgery for implantation or augmentation. Surprisingly, despite the urban situation of the study, lack of awareness turned out to be the most important reason for disparity. For example, the number of patients who had awareness of dental implants was significantly low (6\%).

The study emphasized that in a developing country like India, where the urban population mostly consists of immigrated rural residents, proper awareness of prosthodontic treatment options does not exist. This awareness may come only with time, contact programs and extended prosthodontist-patient interaction including increase use of digital, visual and mechanical educational aids. The last solution is not easy, considering the dentist-patient ratio of India (1:10,000).${ }^{16-18}$ Mobile and satellite dental clinics may be an option, considering that many of the patients requiring prosthodontic treatment may be aging, have compromised physical health and have diminished travel capacity. To counteract financial barriers, dental insurance and social security schemes could be introduced in India. As Watt stated "Health knowledge and awareness are of little value when resources and opportunities to change do not exist". ${ }^{26}$

On the other hand, with increasing levels of literacy and social changes in people, prosthodontists will have to rise to the challenges that will arise from increased prostheses demand, especially with concern to difficult edentulous/ partially dentate conditions. For better service to aging patients, geriatric dental units may need to be established in hospitals along with introduction of syllabi related to geriatric dentistry in the teaching curriculum. ${ }^{27}$

A limitation of this study was the hospital-based sample; the result may not be representative of the population at large. Also, though disparity was noted between the prosthodontist and patient desired treatment option, the number of such patients who actually reported for treatment and the percentage of whose treatment was successfully concluded, was not recorded. Future research could target such areas.

\section{Conclusions}

- Almost half of the population differed in demand and need. The major cause of this disparity was lack of awareness.

- There was limited prosthodontic rehabilitation options awareness.

- Esthetic and health concerns as reasons for requiring prostheses were secondary to masticatory difficulty.

- Demand for dental implants was quite less (6\%), while demand for fixed partial dentures was the most (56\%).

\section{Conflicts of interest}

The authors have none to declare. 


\section{Acknowledgements}

We wish to acknowledge King George's Medical University UP, Lucknow, UP, India for partly financing this research. Thanks are also due to Prof. Ajay Singh, Head, Department of Prosthodontics, Sardar Patel Dental College, Lucknow for his contribution.

\section{R E F E R E N C E S}

1. Chanana HB, Talwar PP. Aging in India: its socioeconomic and health implications. Asia Pac Popul J. 1987;2:23.

2. http://www.thehindubusinessline.com/ industry-and-economy/ per-capita-income-rises-117-in-2012-1-3/article4390227.ece.

3. http://articles.timesofindia.indiatimes.com/2012-10-03/ india/34238401_1_average-life-expectancy-kerala-indian.

4. Esan TA, Olusile AO, Akeredolu PA, Esan AO. Sociodemographic factors and edentulism: the Nigerian experience. BMC Oral Health. 2004;4:3.

5. Fischer HC, Funk GF, Karnell LH, Arcuri MR. Associations between selected demographic parameters and dental status: potential implications for orodental rehabilitation. J Prosthet Dent. 1998;79:526-531.

6. Nadgere J, Doshi AG, Kishore S. An evaluation of prosthetic status and prosthetic need amongst people living in and around Panvel, Navi-Mumbai - a survey. Int J Prosthet Dent. 2010;6-9.

7. Pedersen PH, Vigild M, Nitschke I, Berkey DB. Dental care for aging populations in Denmark, Sweden, Norway, United Kingdom and Germany. J Dent Educ. 2005;987-997.

8. Antczak AA, Branch LG. Perceived barriers to the use of dental services by the elderly. Gerodontics. 1985;1:194-198.

9. Brodeurs JM, Demers M, Simard PL, Kandelman D. Need perception as a major determinant of dental health care utilization among the elderly. Gerodontics. 1988;4:259-264.

10. Mukatash GN, Al-Rousan M, Al-Sakarma B. Needs and demands of prosthetic treatment among two groups of individuals. Indian J Dent Res. 2010;21:564-567.

11. Öwall BE, Taylor RL. A survey of dentitions and removable partial dentures constructed for patients in North America. J Prosthet Dent. 1989;61:465-470.

12. Bradshaw JS. Taxonomy of social need. In: McLaghlan G, ed. In: Problems and Progress in Medical Care 7th ed. Oxford, UK: Oxford University Press; 1972:69-82.
13. Walter $\mathrm{MH}$, Wolf BH, Rieger C, Boening KW. Prosthetic treatment need in a representative German sample. J Oral Rehabil. 2001;28:708-716.

14. Sheiham A, Spencer AJ. Health needs assessment. In: Pine CM, ed. In: Community Oral Health 1st ed. London: Wright Publishers; 1997:39-54

15. Narby B, Kronstorm M, Soderfeldt B, Palmqvist S Prosthodontics and the patient: what is oral rehabilitation need? Conceptual analysis of need and demand for prosthodontic treatment. Part 1: A conceptual analysis. Int J Prosthodont. 2005;18:75-79

16. Singh SV, Tripathi A. A study on prosthodontics awareness and needs of an aging Indian rural population. J Indian Prosthodont Soc. 2007;7:21-23.

17. Singh SV, Tripathi A, Akbar Z, Chandra S, Tripathi A. Prevalence of dental myths, oral hygiene methods and tobacco habits in an ageing North Indian rural population. Gerodontology. 2012;29:e53-e56.

18. Ahuja NK, Parmar R. Demographics \& current scenario with respect to dentists, dental institutions \& dental practices in India. Indian J Dent Sci. 2011;3:8-11.

19. Kumar N, Shekhar C, Kumar P, Kundu AS, Kuppuswamy S. Socio-economic Status Scale - updating for 2007. Indian J Pediatr. 2007;74:1131-1132.

20. D'Souza KM, Aras M. Association between sociodemographic variables and partial edentulism in the Goan population: an epidemiological study in India. Indian J Dent Res. 2014;25:434-438.

21. Akinboboye BO, Shaba OP, Akeredolu PA, Oderinu OH. Sociodemographic determinants of usage of complete dentures in a Nigerian teaching hospital: a pilot study. Eur J Prosthodont. 2013;1:37-41.

22. Vigild M. Benefit related assessment of treatment need among the institutionalized elderly. Gerodontology. 1993;10:10-15

23. Idrees N, Ghani F. Demands, needs, expectations, patterns and reasons among patients for treatment with fixed dental prostheses. JPMI. 2008;22:313-319.

24. Osterberg T, Lundgren M, Emilson CG, Sundh V, Birkhed D, Steen B. Utilization of dental services in relation to socioeconomic and health factors in the middle-aged and elderly Swedish population. Acta Odontol Scand. 1998;56:41-47.

25. Taipale ALS, Nordblad A, Alanen P, Alha P, Koskinen S. Selfreported dental health, treatment need and attendance among older adults in two areas of Finland. Community Dent Health. 2001;18:20-26.

26. Watt RG. Strategies and approaches in oral disease prevention and health promotion. Bull WHO. 2005;83:711-718.

27. Chalmers JM. Geriatric oral health issues in Australia. Int Dent J. 2001;51:188-199. 